Вік.В.Гнатушенко, В.П. Руденко, В.Ю. Царик

\title{
ПРОЕКТУВАННЯ ІТ БІЗНЕС МОДЕЛІ НА ОСНОВІ БЕЗСЕРВЕРНИХ СЕРВИСІВ
}

Анотація. Розвиток інформаційних технологій в бізнесі тягне за собою широке застосування хмарних обчислень: зберігання і обробку даних на стороні компанії, яка надає відповідні Інтернет-сервіси. Тому актуальною є задача дослідження і проектування IT бізнес моделі на основі безсерверніх сервісів, що дозволяє забезпечити доступність для користувачів, зниження витрат на обслуговування віртуальної інфраструктури. У роботі розроблена система з використанням AWS, яка призначена для розробки, проектування та модернізації сучасних «локальних» бізнес моделей, задля підвищення ефективності та економії ресурсів.

Ключові слова: AMAZON WEB SERVICES, модель, проектування.

Постановка проблеми. Останні роки використання хмарних (Cloud) технологій швидко зростає на ринку інформаційних технологій завдяки віртуалізації апаратного середовища, бажанню бізнесу стати мобільнішими, втомі компаній від необхідності оновлювати свої ІТ-системи кожні кілька років, вибуховому зростанню інновацій, що призводить до посилення ринкової конкуренції [1].

Хмарні обчислення вже допомогли багатьом підприємствам провести цифрову трансформацію бізнесу, але ринок Cloud переходить на другу хвилю розвитку період зростання ринку як приватних, так і публічних хмар. Цьому сприяє прагнення підприємств вести бізнес і обслуговувати клієнтів ефективніше: за рахунок масштабування своїх ресурсів, завдяки гнучкості використовуваних технологій, за рахунок можливостей швидкої адаптації компаній під зміни сучасних реалій бізнесу. Тому дослідження та розробка бізнес моделі 3 використанням безсервісних сервісів є актуальною, що дозволить своєчасно і послідовно використовувати сучасні ІT технології.

Аналіз останніх досліджень і публікацій. Можливість використання хмарних інфраструктур все міцніше закріплюється в свідомості власників корпоративних бізнес-рішень (IT-рішень) [2]. Навіть якщо підприємство не робить великих ставок на обчислення в публічних хмарах, використання хмарних рі-

(C) Гнатушенко Вік.В., Руденко В.П., Царик В.Ю., 2021 


\section{«Системні технології» 5 (136) 2021 «System technologies»}

шень в тій чи іншій формі є невід'ємною частиною стратегії і планів розвитку інфраструктури більшості підприємств в силу доступності, економічної ефективності та достатнього рівня надійності.

Amazon Web Services (AWS). AWS є популярним провайдером загальнодоступних хмар з найширшим спектром продуктів, опцій для обчислень і зберігання даних, а також послуг, які клієнт може передати під управління [3]. AWS Marketplace $є$ найбільшим торговим майданчиком для додатків і пристроїв сторонніх виробників. Товари та послуги на такому ринку і сам AWS часто оновлюються, щоб постійно додавати функції продуктів для своїх клієнтів. AWS приділяють велику увагу рекомендаціям з безпеки та архітектури. Корпоративні інфраструктури, такі як Well-Architected Framework i Cloud Adoption Framework, були розроблені на основі досвіду роботи з великими корпоративними клієнтами. Крім основних послуг, вони також випускають нетрадиційні сервіси, такі як SnowMobile (пристрій передачі даних з автомобіля), RoboMaker (фреймворк для робототехніки) i «наземна станція як послуга» (для керованого завантаження даних з супутника).

Хмарне сховище даних поставляється AWS з різними варіантами, такими як динамічна зміна розміру, різні типи дисків (традиційний і SSD). На відміну від інших CSP, AWS не обмежує кількість операцій введення-виведення в секунду (IOPS) за розміром розділу. Сервіс обслуговування реляційних баз даних AWS підтримує керовані бази даних для MySQL, PostgreSQL, MariaDB, Oracle i MS SQL в рамках своєї пропозиції RDS. Крім того, AWS мають свої власні бази даних, сумісні з MySQL i PostgreSQL, які можуть похвалитися продуктивністю, подібної Oracle, але доступні за невелику плату

За останнє десятиліття AWS поліпшив свій портфель мережевих послуг. Він надає керований NAT-шлюз, VPN-шлюз, Transit-шлюз, шлюз прямого доступу і т.д. Для забезпечення безпеки мережі AWS запустила керовані сервіси для захисту від розподілених мережевих атак DDoS (AWS Shield) і брандмауера веб-додатків (WAF), а також AWS Inspector, AWS Config i CloudTrail для управління запасами продуктивності, політиками і аудитом. Сервіс GuardDuty забезпечує виявлення загроз. 3 метою безпеки даних AWS забезпечує шифрування в стані очікування для більшості своїх служб зберігання. AWS також має сервіси KMS i CloudHSM для управління ключами.

Microsoft Azure. Microsoft прийшов пізніше з помітним відставанням від AWS в наданні публічних хмарних сервісів і спочатку зосередився на пропозиціях SaaS i PaaS (програмне забезпечення як послуга і платформа як послуга), 


\section{«Системні технології» 5 (136) 2021 «System technologies»}

оскільки її сильні сторони лежать як в корпоративному, так і в споживчому ПЗ. Згодом Microsoft зробила Azure більш зручною і вбудувала підтримку API для різних сервісів. Однак, незважаючи на широкий спектр послуг, Microsoft iстотно відстає від AWS в корпоративному впровадженні.[4]

Зараз Azure - це зріла хмарна платформа з широким набором функцій, яка може бути кращою платформою для клієнтів, які якимось чином вже використовують продукти Microsoft. Хоча Azure підтримує ряд сервісів на основі продуктів з відкритим вихідним кодом, портфоліо Microsoft в хмарі - це те, що виділяє його серед конкурентів. Azure надає більше 151 типів віртуальних машин і більше 26 сімейств віртуальних машин, які підтримують всі - від невеликих web-систем до навантажень HPC, Oracle i SAP. Azure має як Windows, так і кілька версій Linux (RHEL, CentOS, SUSE, Ubuntu). У Azure $є$ окреме сімейство примірників для роботи з машинним навчанням і штучним інтелектом (ML / AI).

Google Cloud Platform (GCP). Хмарна платформа Google (GCP) має найменшу частку ринку серед постачальників загальнодоступних хмарних обчислень в порівнянні з конкурентами (поточна частка ринку близько 4\%), демонструє стійке відсоткове зростання . 3 точки зору обчислень, Google має найменшу кількість типів віртуальних машин (28 типів примірників по 4 категоріям), але тим не менш, GCP має одну особливість, яка робить ці цифри не такими важливими. Google дозволяє користувачам створювати свої власні нестандартні розміри (процесор, пам'ять), щоб клієнти могли зіставити розміри своїх хмарних навантажень з їх розмірами на попередньому етапі.[5]

Мережеві можливості - це те, де GCP сяє. У Google є глобальна мережа доступу до ресурсів з низькою затримкою. Інші CSP (постачальники хмарних послуг) обмежують мережі VPC в окремому регіоні. Це дозволяє клієнтам GCP створювати додатки, які обслуговують клієнтів по всьому світу, без створення складних міжрегіональних інфраструктурних механізмів і механізмів реплікації даних.

Для реляційних баз даних GCP забезпечує підтримку СУБД MySQL i PostgreSQL. Для клієнтів, яким потрібна глобально розподілена база даних, яка як і раніше підтримує негайну узгодженість і властивості ACID (Atomicity, Consistency, Isolation, Durability). GCР створила Spanner, який використовує узгоджені алгоритми і атомний годинник для синхронізації транзакцій між вузлами. Ця пропозиція є унікальним для GCP і робить Spanner дуже привабливим для великих корпоративних клієнтів, які пред'являють ці вимоги зі свого сховища реляційних даних. Інша СУБД 3 відкритим вихідним кодом 72 


\section{«Системні технологіï» 5 (136) 2021 «System technologies»}

CockroachDB, заснована на описі Spanner, який опублікований Google. 3 точки зору NoSQL, у GCP є продукт під назвою BigTable - це керована база даних NoSQL, яка використовується Google у власних продуктах, таких як Gmail.

Незважаючи на те, що AWS може не володіти достатньою глибиною можливостей деяких інших постачальників хмарних послуг, в його портфелі $\epsilon$ кілька унікальних продуктів, і він $є$ привабливим варіантом використання для розробки та реалізації бізнес додатків.

Метою дослідження є створення сучасної бізнес моделі з використанням безсерверних сервісів та дослідження підходів до її розробки з використанням Amazon Web Services (AWS).

Основна частина. Безсервірні обчислення - природна для хмари архітектура, яка дозволяє передати більшу частину операційної відповідальності AWS і тим самим отримати більше гнучкості та інноваційних можливостей. Вони усувають необхідність займатися питаннями управління інфраструктурою - такими, наприклад, як виділення серверів або кластерів, необхідних ресурсів, а також установка виправлень і обслуговування операційної системи. Їх можна використовувати практично для будь-якого типу додатків або сервісів серверної частини, при цьому все, що потрібно для запуску і масштабування додатки з високою доступністю, виконується без втручання клієнта. Дозволяють створювати більш гнучкі сучасні програми з меншою сукупною вартістю. При створенні додатків розробники можуть зосередитися на основному продукті, не піклуючись про управління серверами, обслуговування серверів або середовищ як в хмарі, так і в локальному місті. Таким чином, розробники зберігають час i сили на розробку відмінних продуктів з високою надійністю і можливістю масштабування.

Amazon CloudWatch - це сервіс моніторингу хмарних ресурсів AWS і додатків, що працюють на AWS. Можна використовувати Amazon CloudWatch для збору і відстеження метрик, накопичення і аналізу логів, а також для створення попереджень. Amazon CloudWatch може вести моніторинг ресурсів AWS (таких як інстанси Amazon EC2, таблиці Amazon DynamoDB, інстанси БД Amazon RDS), призначених для користувача метрик додатків і сервісів, а також моніторинг будь-яких журналів додатків. Amazon CloudWatch можна використовувати для отримання зведеної інформації про систему, включаючи інформацію про використовувані ресурси, продуктивності додатків і загальної працездатності системи. Ці дані застосовуються для оперативного реагування та забезпечення стабільної роботи додатків.[5] 


\section{«Системні технології» 5 (136) 2021 «System technologies»}

AWS X-Ray допомагає розробникам аналізувати свої продукти і розподілені додатки, такі як програми на базі архітектури мікросервісов, а також усувати помилки.

$\mathrm{X}$-Ray допомагає виконувати такі завдання:

- Створювати карти сервісів. X-Rау відстежує запити до додатка і створює карту використовуваних їм сервісів, це дозволяє побачити зв'язки між сервісами додатків, створити дерево залежностей, виявити затримки і помилки при роботі між зонами доступності та регіонами AWS, ідентифікувати сервіси, які працюють неправильно і т. д.

- Ідентифікувати помилки. X-Ray аналізує код, що повертається при обробці кожного запиту до додатка, і автоматично виділяє помилки в коді програми. Це дозволяє легко виправляти помилки в коді програми не відтворюючи їх.

- Створювати власні додатки для аналізу і візуалізації. X-Ray пропонує набір API для запитів, що дозволяють створити власні програми для аналізу і візуалізації на базі зібраних X-Ray даних.

Amazon Simple Notification Service (Amazon SNS) - це веб-сервіс, який спрощує настройку, використання і відправку повідомлень з хмари. у сервісу Amazon SNS є ряд переваг, які роблять його практичним рішенням для створення і інтеграції слабосвязанних розподілених додатків:

- Миттєва доставка на основі технології push (без опитувань).

- Прості інтерфейси API і зручна інтеграція з додатками.

- Гнучка доставка повідомлень по декількох протоколах передачі.

- Економічний тарифний план, що передбачає оплату за фактом використання, без попередніх платежів.

- Консоль управління AWS з простим інтерактивним веб-інтерфейсом.

Сфера застосування Amazon SNS дуже широка: повідомлення про події, додатки моніторингу, системи управління робочими процесами, оновлення термінової інформації, мобільні додатки, а також будь-які інші програми, для яких актуальна відправка або отримання повідомлень. Наприклад, в системах управління робочими процесами Amazon SNS можна використовувати для трансляції подій всередині розподілених обчислювальних систем, перенесення даних між сховищами або поновлення записів в бізнес-системах.

Проектування бізнес моделі. В роботі розроблено контекстну модель створення інтернет магазину за методологією IDEF0 (методологія функціонального моделювання і графічна нотація, призначена для формалізації і опису 74 
«Системні технології» 5 (136) 2021 «System technologies»

бізнес-процесів). На рисунку 1 приведена модель IDEF0, що описує основні етапи створення інтернет магазину.

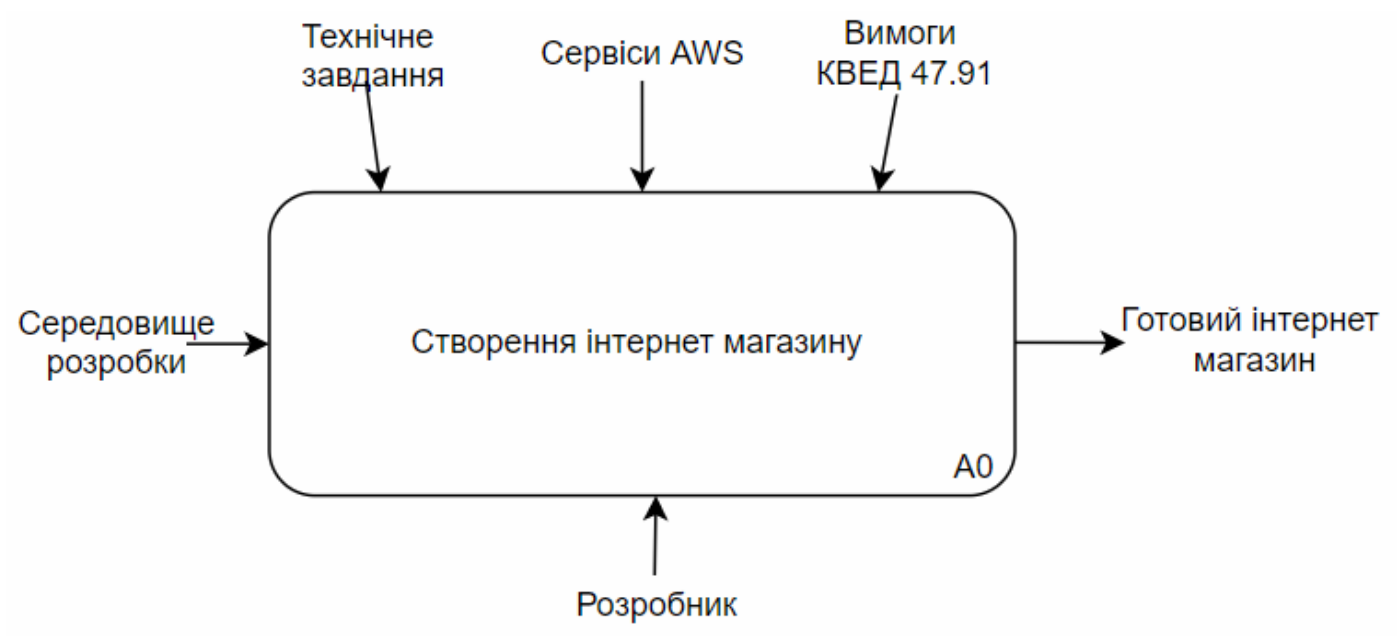

Рисунок 1 контекстна діаграма IDEF0

Взаємодія функцій між собою і зовнішнім світом описується:

- вхідним потоком даних - середовище розробки;

- потоком управління -технічне завдання замовника, сервіси AWS, вимогИ КВЕД;

- вихідним потоком - матеріальний об'єкт або інформація, які представляють результат виконання функції розроблений інтернет магазин;

- механізмами - ресурси, які задіяні при виконанні функції - розробник.

Також розроблено Use Case (варіант використання) - сценарна техніка опису взаємодії. За допомогою Use Case визначено вимоги користувача, взаємодії окремих частин (модулів) систем, описано взаємодії людей і компаній в реальному житті. Приклад діаграми Use Case інтернет магазину наведено на рисунку 2.

На етапі проектування розроблено діаграму діяльності, яка відображає порядок дій об'єктів в часі та подання часових особливостей передачі і прийому повідомлень між об'єктами (рисунок 3). На діаграмі діяльності з оформлення замовлення зображені тільки ті об'єкти, які беруть участь у взаємодії, і не показуються можливі статичні асоціації з іншими об'єктами. 
«Системні технології» 5 (136) 2021 «System technologies»
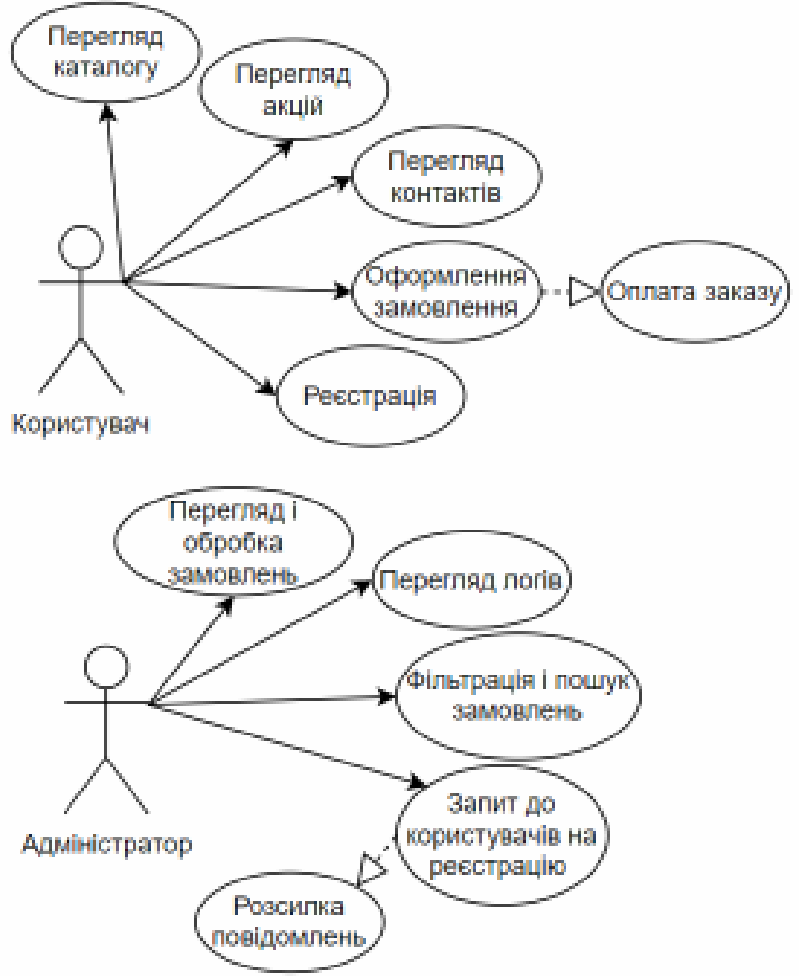

Рисунок 2 - Диаграмма Use-Case

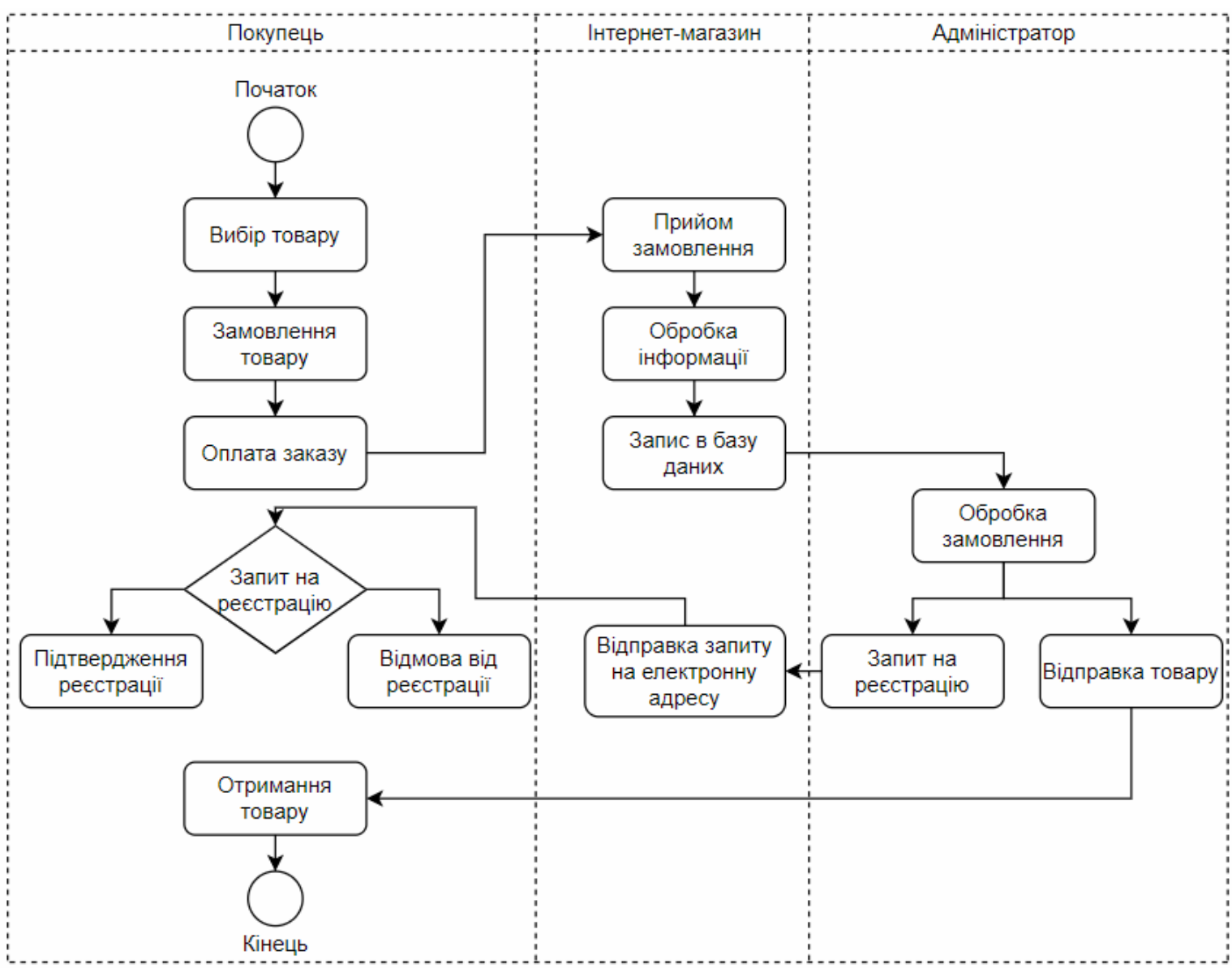

Рисунок 3 Діаграма діяльності 
«Системні технології» 5 (136) 2021 «System technologies»

Реалізація бізнес моделі. Проаналізувавши поставлені задачі, було вирішено реалізувати систему на мові JavaScript, HTML, CSS та за допомогою технологій IntelliJ IDEA, PostgreSQL, Spring boot, Hibernate, Thymeleaf, CUBA platform, AWS.

В даній моделі використовується структура sandbox-shop та класів: Transaction, ClientReq, TransactionBuilder, TransactionRepository, TransactionService, ClientController, SandboxApplication, ObjectMapperConfig, WebConfig, WebSecurityConfig.Структура sandbox-shop використовується для представлення послуг покупцям.

Опис класів-членів, що містить структура sandbox-shop наведено ннижче:

- Transaction - базова модель, що зберігається в БД;

- ClientReq - базовий запит від клієнта;

- TransactionBuilder - статичний клас для побудови моделі транзакції. Винесено в окремий клас для реалізації паттерна - builder;

- TransactionRepository - інтерфейс, який реалізує патерн репозиторію тобто взаємодія з базою даних за допомогою моделей;

- TransactionService - клас-обгортка над transactionRepository (для логування);

- ClientController - клас, який реалізує REST API (надання HTTP 2.0 точок доступу до сервісу);

- SandboxApplication-Execution - клас всього додатку (запускає арр);

- ObjectMapperConfig - налаштування REST API сериализации запитів;

- WebConfig - підключення сериализации запитів;

- WebSecurityConfig - налаштування web security для додатка.

Висновки. У статті виконано дослідження підходів проектування моделей з використанням Amazon Web Services, проведено порівняльний аналіз використання хмарних серверів. На основі проведеного аналізу зроблено висновок про доцільність використання AWS при розробці додатків з використанням безсерверних сервісів для забезпечення масштабування та адаптивності.

Розроблена система з використанням AWS, яка призначена для розробки, проектування та модернізації сучасних «локальних» бізнес моделей, задля підвищення ефективності та економії ресурсів, як приклад розроблено інтернет магазин. Дана робота корисна при проектування та створенні IT бізнес моделі.

\section{ЛІТЕРАТУРА / ЛИТЕРАТУРА}

1. Suyog Bankar.Cloud Computing Using Amazon Web Services (AWS) / Bankar Suyog // International Journal of Trend in Scientific Research and Development 
«Системні технології» 5 (136) 2021 «System technologies»

(ijtsrd), ISSN: $\quad$ 2456-6470.2018.Volume-2, Issue-4.p.2156-2157. URL: https://www.ijtsrd.com/papers/ijtsrd14583.pdf

2. Abdullah Alqahtani, Hina Gull. Cloud Computing and Security Issues/ Alqahtani Abdullah, Gull Hina // International Journal of Applied Engineering Research ISSN 0973-4562 Volume 13, Number 22. 2018. p. 16077-16084. URL https://www.ripublication.com/ijaer18/ijaerv13n22_87.pdf

3. Inc. Amazon Web Services. Amazon [Електронний ресурс]. - Режим доступу: https://aws.amazon.com/ (дата звернення: 12.02.2021)

4. Документация по Azure: [Електронний ресурс]. - Режим доступу: https://docs.microsoft.com/ru-ru/azure/?product=featured (дата звернення: 12.02.2021)

5. Build solutions on Google Cloud: [Електронний ресурс]. - Режим доступу: https://cloud.google.com/docs (дата звернення: 12.02.2021)

\section{REFERENCE}

1. Suyog Bankar .Cloud Computing Using Amazon Web Services (AWS) / Bankar Suyog // International Journal of Trend in Scientific Research and Development (ijtsrd), ISSN: 2456-6470.2018.Volume-2, Issue-4.p.2156-2157. URL: https://www.ijtsrd.com/papers/ijtsrd14583.pdf

2. Abdullah Alqahtani, Hina Gull. Cloud Computing and Security Issues/ Alqahtani Abdullah, Gull Hina // International Journal of Applied Engineering Research ISSN 0973-4562 Volume 13, Number 22. 2018. p. 16077-16084. URL https://www.ripublication.com/ijaer18/ijaerv13n22_87.pdf

3. Inc. Amazon Web Services. Amazon [Електронний ресурс]. - Режим доступу: https://aws.amazon.com/ (the date of application: 12.02.2021)

4. Документация по Azure: [Електронний ресурс]. - Режим доступу: https://docs.microsoft.com/ru-ru/azure/?product=featured (the date of application: 12.02.2021)

5. Build solutions on Google Cloud: [Електронний ресурс]. - Режим доступу: https://cloud.google.com/docs (the date of application: 12.02.2021)

Received 29.04.2021. Accepted 05.05.2021.

\section{Проектування IT бізнес моделі на основі безсерверних сервисів}

Аналіз існуючих хмарних сервісів, які надають можливість створення безсерверних сервісів для проектування систем та зберігання даних, забезпечують кібербезпеку мережевих додатків. Розроблена система з використанням AWS (Amazon Web Services), яка призначена для розробки, проектування та модернізації сучасних «локальних» бізнес моделей, задля підвищення ефективності та економії ресурсів. 


\section{«Системні технологіï» 5 (136) 2021 «System technologies»}

\section{Design of it business model on the basis of serverless services}

The last researches and publications analysis. Cloud technologies are rapidly deploying in the information technology market due to the virtualization of the hardware environment and the desire of businesses to become more mobile. Amazon Web Services (AWS) is a cloud environment that has low advantages: it does not limit the number of I / 0 operations per second (IOPS) by partition size. The AWS relational database service supports managed databases for MySQL, PostgreSQL, MariaDB, Oracle and MS SQL as part of its RDS offering. AWS has its own databases compatible with MySQL and PostgreSQL, which have performance like Oracle, but are available for a small fee. Azure is a mature cloud platform with a wide range of features that can be the best platform for customers who somehow already use the products. Microsoft. Although Azure supports a number of services based on open source products, Microsoft's portfolio in the cloud is what sets it apart from the competition. Google Cloud Platform (GCP) has the smallest market share among public cloud computing providers In terms of computing, Google has the fewest types of virtual machines (28 types of instances in 4 categories), but nevertheless, GCP allows users to create their own custom dimensions (processor, memory) so that customers can compare the size of their cloud loads with their size at the previous stage.

The aim of the research. Creating a modern business model using server-free services and researching approaches to its development using Amazon Web Services (AWS).

The main research material.

The paper develops a contextual model of creating an online store according to the methodology IDEFO (methodology of functional modeling and graphical notation, designed to formalize and describe business processes), which describes the main stages of creating an online store. Developed Use Case (use case), which determines the requirements of the user, the interaction of individual parts (modules) of systems, describes the interaction of people and companies in real life. At the design stage, a diagram of activities is developed, which reflects the order of action of objects in time and the presentation of temporal features of transmission and reception of messages between objects. The IT business model is implemented in JavaScript, HTML, CSS and with the help of IntelliJ IDEA, PostgreSQL, Spring boot, Hibernate, Thymeleaf, CUBA platform, AWS technologies.

Conclusions. The article presents a comparative analysis of the use cloud technologies. Based on the analysis of model design approaches, a conclusion was made about the feasibility of using AWS in the development of applications using server-free services to ensure scalability and adaptability. Developed a system using AWS, which is designed to develop, design and upgrade modern "local" business models, to increase efficiency and save resources, as an example, developed an online store. 
Гнатушенко Вікторія Володимирівна - доктор технічних наук, професор, професор кафедри інформаційних технологій і систем Національної металургійної академії України.

Руденко Вячеслав Павлович -студент Національної металургійної академії України (НМетАУ).

Царик Владислав Юрійович - аспірант, асистент кафедри інформаційних технологій і систем Національної металургійної академії України.

Гнатушенко Виктория Владимировна - доктор технических наук, професcop, профессор кафедры информационных технологий и систем Национальной металлургической академии Украины.

Руденко Вячеслав Павлович студент Национальной металлургической академии Украины.

Царик Владислав Юрьевич - аспирант, ассистент кафедры информационных технологий и систем Национальной металлургической академии Украины.

Hnatushenko Viktoriia - Doctor of engineering's sciences, Professor, Department of Information Technologies and Systems, National Metallurgical Academy of Ukraine.

Rudenko Vyacheslav -the student of National Metallurgical Academy of Ukraine.

Tsaryk Vladyslav - Postgraduate Student, Assistant Professor, Department of Information Technologies and Systems, National Metallurgical Academy of Ukraine. 